\title{
Research on Partner Selection of Landscaping Business Supply Chain Based on G1 and Gray Correlation Method
}

\author{
Meng SHEN, Shaowen ZHANG \\ School of Economics and Management \\ Beijing Forestry University \\ BeiJing 100083, China
}

\author{
Zhuanyun QIAO \\ Beijing Forestry University Forest Science Co.LTD \\ BeiJing 100083, China
}

\begin{abstract}
Good supply chain collaboration between enterprises is an important foundation for supply chain management to achieve good results, selecting the appropriate supply chain partners will decide whether this benign cooperative relations could be smoothly established. This paper establishes the landscape engineering project management model, based on the analysis to identify landscaping supply chain partners, take landscaping projects for example, it has established the evaluation system of landscaping project suppliers and use combined approach of G1 method and gray correlation method to establish the index weight and evaluation methods, and given the scientific supply chain partners evaluation and selection process which is easy to operate to solve the selection problem of landscaping supply chain partners.
\end{abstract}

Keywords- landscaping companies; Supply chain partnerships; G1; Gray correlation analysis

\section{INTRODUCTION}

The entire supply chain should be successfully operated for enterprises to win in the competition. As an important link in supply chain management, selecting the appropriate supply chain partners is the basis for enterprises to establish an efficient supply chain alliance. Thinking and scientific supplier selection method is still limited at this stage of supply chain management, and related research is extremely limited in the landscaping industry applications, which results in low levels of construction management, high management costs, and companies are passively endured great risk fluctuations in raw material prices to some extent.

The general research process of supply chain partner selection problem can be divided into four steps: evaluation determination, giving index weight, selecting evaluation methods and partner selection. The study of partner selection problem for landscaping companies in this paper is based on the framework of this study. In the process of actual selection of supply chain partners, it should be based on this process to select to determine the appropriate evaluation and corresponding weights, take the appropriate method to evaluate and finally choose their supply chain partners.

\section{SUPPLY CHAIN PARTNERS IDENTIFICATION IN LANDSCAPING COMPANIES}

To select supply chain partners, you need to identify the business partners. To understand the landscaping business partners, you need to first study to confirm the management model of garden project. The garden project management is conducted according to BDBB (Bid-Design-Bid-Build) model, namely, implementation is in accordance with the tender design - design - construction tender - construction process, the main participants in the project include owners, project supervision, designers, outdoor landscape engineering, engineering subcontractors and material suppliers, and the need of owners is the core of the entire project. Designers are responsible for the design drawings and related engineering. In order to facilitate the supervision and management and confirm landscape engineering can be completed on schedule with good quality and quantity, the owners also need to hire a construction supervision who is responsible for supervising the work dynamically, outdoor landscape project contractors are responsible for the construction in accordance with engineering drawings, and deliver completed projects to owners on time. At the same time, the contractor may undertake part of their sub-projects to other construction subcontractors, material suppliers are responsible for providing all the necessary sub-projects garden plants, civil engineering, pipelines and other raw materials. Currently the landscape engineering project management model is as follows:

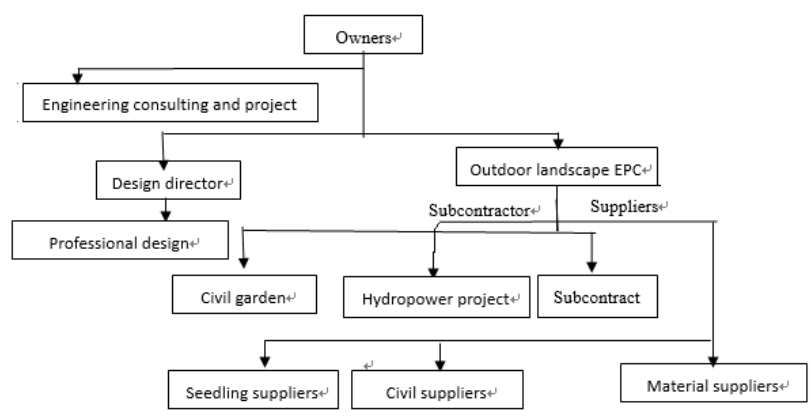

Fig.1 landscape engineering project management model As can be seen from Fig.1, as a landscaping business (outdoor landscape EPC), the main partner is engineering subcontractors and material suppliers. Since the 
whole garden project is composed of a plurality of subprojects, different sub-projects also correspond to different material suppliers, in order to highlight the features of the garden project, the paper selects landscaping projects supplier (nursery supplier) as an object to study the selection method.

\section{BUILDING OF LANDSCAPING SUPPLIER EVALUATION SYSTEM}

In the selecting research of evaluation, in year 1966, the study of American scholar Dickson had a great impact on supplier selection. With 273 agents and managers survey, Dickson summed up 23 vendors and sorting criteria and weights to select ${ }^{[1]}$, on the basis of evaluation studies of these suppliers, combined with the actual situation in landscaping projects, the paper makes the following research on index landscaping projects.

General construction implementation object is steel, cement, wood, sand, stone and other building materials, and landscaping projects implementation objects are most of life. Through a variety of coleus plants, garden flowers, ground cover planting lawns and configuration, using a variety of special features seedlings to purify the air, vacuum cooling, noise sterilization, create a suitable environment for tourism and leisure space. Plant material of landscaping project has large changes in market prices, which is difficult to grasp ${ }^{[2]}$. A comprehensive landscaping project will use dozens or even hundreds of species (size) of the plant material, if for every plant material, we have chosen a different vendor to offer, the cost will be too high, and the subsequent management will be very inconvenient. So for landscaping businesses, to choose suppliers landscaping projects must also put emphasis on the seedling nursery supplier base conditions. Whether nursery suppliers have a certain proportion of professional and technical personnel are able to influence the quality of the raw material that provides the plant to some extent, along with a certain level of technology seedling suppliers, not only to provide the plant material in accordance with the requirements, but also may help landscaping business select and improve plant species, such as the same kind of seedlings due to changes in season, there will be a big price volatility, which gives operators landscaping business that has brought great difficulties, which is not conducive to carry out the project cost. High level of technology and outstanding innovation capability provider may give different planting seedlings proposal in different seasons, and may also introduce some new varieties to replace the original variety.

Based on these unique properties of seedling material, landscaping projects suppliers should also establish the corresponding characteristic evaluation. This paper divides the evaluation index of landscaping projects suppliers into two parts: general index and unique index.

(1) General index. General index refers to the indicators that general supplier selection process needs to consider, which is applicable for most of the vendor selection problem. Combined with the actual situation of landscaping projects, these indicators are as follows:
Tab 1 General Index of landscaping supplier evaluation

General Index

Index description

A1 price Provide price of seedlings green

project requires

A2 quality Whether the provided quality seedlings

meet the needs of greening projects

A3 delivery

The time interval between

order and receipt

A4 partnership The supplier performance and

partnership in the former cooperation process

A5 past traffic

The business volume in

former collaboration

A6 cooperative attitude

Attitude of

suppliers is enthusiastic or not

A7 support services Whether the supplier offer seedlings logistics and other support services

(2)

Unique index. General index is considered mostly, but due to that seedling material has the characteristics discussed above, the seedlings suppliers establish a unique index in the table below.

Tab 2 Unique Index of landscaping supplier evaluation

Unique index Index description

A8 Seedlings base status Seedlings base size, location, seedling varieties, nursery stock

A9technical level Whether nursery has a certain level of expertise

\section{LANDSCAPING WORKS SUPPLIER SELECTION PROCESS}

\section{A. Evaluation of the weight confirm}

After confirming the evaluation index of landscaping business partners, we need to distinguish the importance level of each index. Confirming index weight method is mainly divided into qualitative method, combining qualitative and quantitative method and quantitative method. G1 method is an improved method based on AHP method, which is improved by AHP, avoids the shortcomings of AHP method. The matrix structure is not required to determine the index weight in the process, no consistency check, and calculation is significantly reduced [3-4].

1) G1 method is calculated as follows:

(1) Establish order relations. If the degree of importance of the evaluation $x_{i}$ relative to certain evaluation criteria is greater than $x_{j}$, denoted as $x_{i}>x_{j}$. If the index set $\left\{x_{1}, x_{2}, \ldots\right.$, 
$x_{m}$ \} with respect to the evaluation criteria have some relationship $x_{i}>x_{j}>\ldots x_{k}(i, j, \ldots, k=1,2 \ldots, m)$, I ca be claimed that the $m$ evaluation index establishes order relation in accordance with the " $>$ ".

(2) Experts determine the ratio of weight between neighboring rights. An important indicator extent of the ratio can be used

$$
\mathrm{r}_{\mathrm{k}}=\mathrm{w}_{\mathrm{k}-1} / \mathrm{w}_{\mathrm{k}} \mathrm{k}=2,3, \ldots, \mathrm{m}-1, \mathrm{~m}
$$

to represent, where $\mathrm{w}_{\mathrm{n}}, \mathrm{n}=1,2,3, \ldots, \mathrm{m}$, represents the first evaluation indexes.

(3) Calculate the weight coefficients. If rational values given by experts satisfies $r_{k-1}>1 / r_{k}$, then $w_{m}$ is:

$$
\mathrm{W}_{\mathrm{m}}=\left[1+\sum_{k=2}^{m} \prod_{i=k}^{m} r_{i}\right]^{-1},
$$

$\mathrm{w}_{\mathrm{k}-1}=\mathrm{r}_{\mathrm{k}} * \mathrm{w}_{\mathrm{k}}, \mathrm{k}=\mathrm{m}, \mathrm{m}-1, \mathrm{~m}-2, \ldots, 3,2$,

These two formulas can be proved in Ref. [3] and [5]. In the formula, $w_{k}$ means the Kth weight indicator. After expert evaluation, the order relations and neighboring rights weight ratio of landscaping projects are determined as follows:

Tab 3 G1 survey results

\section{Rank Evaluation index Neighboring rights weight ratio}

$\begin{array}{lc}1 & \text { Seedlings base status } \\ 2 & \text { Quality } \\ 3 & \text { Price } \\ 4 & \text { Delivery } \\ 5 & \text { Support services } \\ 6 & \text { Historical performance } \\ 7 & \text { Past traffic } \\ 8 & \text { Technical level } \\ 9 & \text { Cooperative attitude }\end{array}$

As can be seen from the results of the evaluation, in the choice of landscaping projects suppliers, the most concerned five indicators were seedlings base status, quality, price, delivery, and support services. The heavy weight of each evaluation index is calculated as follows, according to (3) in Equation 1 shows that:

$\mathrm{W} 9=[(1+\mathrm{r} 2 * \mathrm{r} 3 * \ldots \mathrm{r} 9++\mathrm{r} 3 * \mathrm{r} 4 * \ldots * \mathrm{r} 9+\mathrm{r} 4 * \mathrm{r} 5 * \ldots * \mathrm{r} 9+\ldots+\mathrm{r} 7$ $* \mathrm{r} 8 * \mathrm{r} 9+\mathrm{r} 8 * \mathrm{r} 9+\mathrm{r} 9)]^{-1}=0.0459$

According to Equation 2 in (3), evaluation right weight $\mathrm{w}$ value can be calculated, the final weight matrix is:

$\mathrm{W}=(0.1746,0.1746,0.1455,0.1323,0.1102,0.0848,0.0771$, $0.0551,0.0459)$

2) Supplier selection of landscaping subproject

Gray correlation analysis method [6-7] is a gray system analysis. Based on the degree of similarity or dissimilarity between the trends of factors, namely the "gray correlation degree", as a method to measure the degree of association between factors.

(1) Data standardization and construction reference series. Suppose there are $\mathrm{n}$ seedling suppliers to choose from, each seedling supplier $\mathrm{m}$ has a corresponding evaluation value column, m suppliers have the number of columns m. namely:

$$
\mathrm{Y}_{1}=\left\{\mathrm{y}_{1}(1), \mathrm{y}_{1}(2), \ldots, \mathrm{y}_{1}(9)\right\} \quad ;
$$

$\mathrm{Y}_{2}=\left\{\mathrm{y}_{2}(1), \mathrm{y}_{2}(2), \ldots, \mathrm{y}_{2}(9)\right\} ; \ldots ; \quad \mathrm{Y}_{\mathrm{m}}=\left\{\mathrm{y}_{\mathrm{m}}(1), \mathrm{y}_{\mathrm{m}}(2), \ldots, \mathrm{y}_{\mathrm{m}}(9)\right\}$

Where the values of $Y_{p}(q)$ represents the qth indicator of the $\mathrm{p}$ vendor.

For all indicators, because of the different dimension, data standardization need to be carried out before calculating: the greater the value, the better the efficiency indicators. For the benefit index, take the following standardized way:

$$
\frac{y_{p}(q)-\min _{p} x_{p}(q)}{\max _{p} x_{p}(q)-\min _{p} x_{p}(q)}
$$

For cost index, take the following standardized way:

$$
\mathrm{z}_{\mathrm{p}}(\mathrm{q})=\frac{\max _{p} x_{p}(\mathrm{q})-y_{p}(q)}{\max _{p} x_{p}(\mathrm{q})-\min _{p} x_{p}(q)}
$$

(2) Construct reference series. Construct a reference sequence determine the expected value of each index number of columns, in theory, there are two ways to build this series, one is giving an optimal value in advance, that reference sequence can be expressed as: $\mathrm{C}_{1}=\left(\mathrm{E}_{1}, \mathrm{E}_{2}, \mathrm{E}_{2}, \ldots, \mathrm{E}_{9}\right)$ Another way is to select the optimal value of each evaluation index n, namely,

Efficiency indicators: $\operatorname{opt}(\mathrm{q})=\max \left(\mathrm{z}_{\mathrm{p}}(\mathrm{q})\right)$, Cost index: $\operatorname{opt}(\mathrm{q})=\min \left(\mathrm{z}_{\mathrm{p}}(\mathrm{q})\right)$

opt $(q)$ represents the optimal value of the $q$-th index, the value $z_{p}(q)$ is on behalf of the $p$-q-th vendor evaluation index, $\mathrm{p}=1,2, \ldots, \mathrm{n}$

(3) Calculate the gray correlation coefficient and gray correlation. Grey correlation coefficient is calculated using the following formula can be:

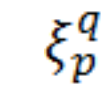

$=$

$$
\frac{\min _{s} \min _{t}\left|x_{0}(t)-x_{s}(t)\right|+\rho \max _{s} \max _{t}\left|x_{0}(t)-x_{s}(t)\right|}{\left|x_{0}(q)-x_{p}(q)\right|+\rho \max _{s} \max _{q}\left|x_{0}(q)-x_{s}(q)\right|}
$$

Where, ${ }^{\xi_{p}^{q}}$ means the gray correlation coefficient of suppliers, where $\rho$ is resolved coefficients. Generally speaking, $\rho \epsilon[0,1]$. The bigger $\rho$ is, the greater the resolution. The smaller $\rho$ is, the smaller the resolution. The value of $\rho$ is often 0.5.

$$
\min _{s} \min _{t}\left|x_{0}(t)-x_{s}(t)\right| \text { 和 } \rho \max _{s} \max _{t}\left|x_{0}(t)-x_{s}(t)\right|
$$

means the minimum and maximum levels. Then for any nursery supplier $\mathrm{n}$, its gray correlation coefficient matrix is constructed as follows: $\mathrm{R}_{\mathrm{n}}=\left(\zeta_{\mathrm{n}}^{1} \xi_{\mathrm{n}}^{2} \ldots \xi_{\mathrm{n}}^{9}\right)$ 


\section{CASE STUDY}

Taking a landscaping business for the study, according to the research index scoring system, respectively, nine indicators for each vendor scoring, scoring results are as follows:

Tab 4 Supplier Scorecard

\begin{tabular}{|c|c|c|c|c|c|}
\hline \multicolumn{3}{|l|}{ Evaluation index } & \multicolumn{3}{|c|}{ Supplier Scorecard } \\
\hline $\bar{A}$ & $\bar{A}$ & $\overline{\mathbf{B}}$ & $\mathbf{C}$ & $\overline{\mathbf{D}}$ & $\overline{\mathbf{E}}$ \\
\hline Seedlings base status & 9 & 8.5 & 7 & 7.6 & 8 \\
\hline Quality & 8.5 & 9 & 8.8 & 9.5 & 8.6 \\
\hline Price & 200 & 180 & 210 & 190 & 195 \\
\hline Delivery & 1.5 & 3 & 2 & 1.2 & 1 \\
\hline Support services & 8 & 8 & 9 & 8 & 8 \\
\hline Historical performance & 7 & 8 & 8 & 9 & 9 \\
\hline Past traffic & 50000 & 30000 & 25000 & 8000 & 11000 \\
\hline Technical level & 0.3 & 0.2 & 0.15 & 0.18 & 0.22 \\
\hline Cooperative attitude & 9 & 10 & 8 & 9 & 9 \\
\hline
\end{tabular}

Research methods as described above, after the first standardization of these data to build the optimal matrix for each indicator $\mathrm{C}_{0}=(1,1,1,1,1,1,1,1,1,1,1)$ Grey correlation matrix $\mathrm{C}=\left(\mathrm{C}_{0}, \mathrm{C}_{\mathrm{A}}, \mathrm{C}_{\mathrm{B}}, \mathrm{C}_{\mathrm{C}}, \mathrm{C}_{\mathrm{D}}, \mathrm{C}_{\mathrm{E}}\right)^{\mathrm{T}}$

Namely,

$\mathrm{C}=$

$\left(\begin{array}{ccccccccc}1 & 1 & 1 & 1 & 1 & 1 & 1 & 1 & 1 \\ 1 & 0 & 0.33 & 0.75 & 0 & 0 & 1 & 1 & 0.5 \\ 0.75 & 0.5 & 1 & 0 & 0 & 0.5 & 0.52 & 0.33 & 1 \\ 0 & 0.3 & 0 & 0.5 & 1 & 0.5 & 0.4 & 0 & 0 \\ 0.3 & 1 & 0.67 & 0.9 & 0 & 1 & 0 & 0.2 & 0.5 \\ 0.5 & 0.1 & 0.5 & 1 & 0 & 1 & 0.07 & 0.47 & 0.5\end{array}\right)$

After calculation, this five suppliers's correlation coefficient matrix:

$\left.\begin{array}{ccccccccc}\mathrm{R}= & & & & & & & & \\ 1 & 0.33 & 0.43 & 0.67 & 0.33 & 0.33 & 1 & 1 & 0.5 \\ 0.67 & 0.5 & 1 & 0.33 & 0.33 & 0.5 & 0.51 & 0.43 & 1 \\ 0.33 & 0.42 & 0.33 & 0.5 & 1 & 0.5 & 0.45 & 0.33 & 0.33 \\ 0.42 & 1 & 0.6 & 0.83 & 0.33 & 1 & 0.33 & 0.38 & 0.5 \\ 0.5 & 0.36 & 0.5 & 1 & 0.33 & 1 & 0.35 & 0.49 & 0.5\end{array}\right)$

Calculation of gray correlation is $\mathrm{A}=\mathrm{R}^{*} \mathrm{~W}^{\mathrm{T}}=(0.6033$, $0.5812,0.4669,0.6366,0.5529)^{\mathrm{T}}$

$\operatorname{Max} A_{n}=A_{4}=0.6366$, so we choose D.

\section{CONCLUSION}

Garden project is an integrated project, due to the current low level of the garden project management, resulting in problems such as the slow progress of construction project and higher management costs. Therefore, the implementation of supply chain management is necessary, and the introduction of scientific management methods of various aspects of supply chain management is particularly important and urgent, as a key issue, the supply chain partner selection problem need to attract more attention of landscaping companies in supply chain management. This paper presents choose a combining method of G1 and gray correlation analysis which scientific and easy to operate, easy to use in engineering practice. It should be noted that this article is established based on the evaluation index system suppliers as landscaping projects target in the evaluation of other subprojects and subcontractors, the evaluation process may be consistent with this article, you will need to make the appropriate index system vary according to the actual situation, which can be continuously improved and supplemented in the future course of study and practice.

\section{References}

[1] Dickson G W. An analysis of vendor selection systems and decisions[J]. Journal of purchasing. 1966, 2(1): 5-17.

[2] Lv J. Features and management of landscaping project [J]. Private Technology, 2010 (09).

[3] Guo Y. Evaluation theory and methods [M]. Beijing: Science Press, 2002.

[4] Wang X, Guo Y. The consistency analysis of judgment matrix based on G1 method [J]. China Management Science, 2006, 6 (3): 65-70.

[5] Liu C, Wang F, et al. Robust $\mathrm{H} \infty$ Control for Satellite Attitude Control System with Uncertainties and Additive Perturbation [J]. International Journal of Science, 2014, 1(2): 1-9.

[6] Lin P. Analysis and application of gray correlation [J]. Salt Lake Research .2001 (02)

[7] Liu C, Wang F. Mixed $\mathrm{H} 2 / \mathrm{H} \infty$ control for a satellite based on LMI[C]. // Mechatronics and Control (ICMC), 2014 IEEE International Conference on. IEEE, 2014: 2114-2118. 